\title{
Anticholinergic Use and Recurrent Falls in Community-Dwelling Older Adults: Findings From the Health ABC Study
}

\author{
Zachary A. Marcum, PharmD, PhD ${ }^{1}$, Subashan Perera, $\mathrm{PhD}^{2}$, Joshua M. Thorpe, $\mathrm{PhD}^{2,3}$, \\ Galen E. Switzer, $\mathrm{PhD}^{2,3}$, Shelly L. Gray, PharmD, MS ${ }^{1}$, Nicholas G. Castle, $\mathrm{PhD}^{2}$, Elsa S. \\ Strotmeyer, $\mathrm{PhD}^{2}$, Eleanor M. Simonsick, $\mathrm{PhD}^{4}$, Douglas C. Bauer, $\mathrm{MD}^{5}$, Ronald I. Shorr, \\ MD, MS ${ }^{6}$, Stephanie A. Studenski, MD, MPH ${ }^{4}$, Joseph T. Hanlon, MS, PharmD ${ }^{2,3}$, and the \\ Health ABC Study, USA \\ ${ }^{1}$ University of Washington, Seattle, WA, USA \\ 2University of Pittsburgh, Pittsburgh, PA, USA \\ ${ }^{3}$ VA Pittsburgh Healthcare System, Pittsburgh, PA, USA \\ ${ }^{4}$ National Institute on Aging, Baltimore, MD, USA \\ ${ }^{5}$ University of California, San Francisco, CA, USA \\ ${ }^{6}$ Veterans Affairs Medical Center, Gainesville, FL, USA
}

\section{Abstract}

Background-Although it is generally accepted that anticholinergic use may lead to a fall, results from studies assessing the association between anticholinergic use and falls are mixed. In addition, direct evidence of an association between use of anticholinergic medications and recurrent falls among community-dwelling elders is not available.

Objective-To assess the association between anticholinergic use across multiple anticholinergic subclasses, including over-the-counter medications, and recurrent falls.

\begin{abstract}
Methods-This was a longitudinal analysis of 2948 participants, with data collected via interview at year 1 from the Health, Aging and Body Composition study and followed through year 7 (1997-2004). Self-reported use of anticholinergic medication was identified at years 1, 2, 3, 5, and 6 as defined by the list from the 2015 American Geriatrics Society Beers Criteria. Dosage and duration were also examined. The main outcome was recurrent falls ( $\geq 2)$ in an ensuing 12month period from each medication data collection.
\end{abstract}

Results-Using multivariable generalized estimating equation models, controlling for demographic, health status/behaviors, and access-to-care factors, a $34 \%$ increase in likelihood of recurrent falls in anticholinergic users (adjusted odds ratio $=1.34 ; 95 \% \mathrm{CI}=0.93-1.93$ ) was

\footnotetext{
Reprints and permissions: sagepub.com/journalsPermissions.nav

Corresponding Author: Zachary A. Marcum, Department of Pharmacy, School of Pharmacy, University of Washington, 1959 NE Pacific St, H375G, Box 357630, Seattle, WA 98102, USA. zmarcum@uw.edu.

This work was presented in part at the Gerontological Society of America's Annual Scientific Meeting on November 8, 2014.

Declaration of Conflicting Interests

The author(s) declared no potential conflicts of interest with respect to the research, authorship, and/or publication of this article.
} 
observed, but the results were not statistically significant; similar results were found with higher doses and longer duration of use.

Conclusion-Increased point estimates suggest an association of anticholinergic use with recurrent falls, but the associations did not reach statistical significance. Future studies are needed for more definitive evidence and to examine other measures of anticholinergic burden and associations with more intermediate adverse effects such as cognitive function.

\section{Keywords}

cholinergic antagonist; accidental falls; older adults; pharmacoepidemiology

\section{Introduction}

Anticholinergic medication use is common in older adults, with $13 \%$ to $25 \%$ of communitydwelling older adults taking at least one agent, despite concerns for adverse effects. ${ }^{1-4}$ An estimated $18 \%$ to $40 \%$ of community-dwelling elderly people fall annually, ${ }^{5-7}$ with nearly $50 \%$ falling more than once and up to $10 \%$ sustaining a serious injury, including hip fracture with related morbidity and mortality. ${ }^{8}$ Recurrent falls (as opposed to single falls) may be more clinically important because they may identify older adults with an increased risk of physical and cognitive status problems rather than a random event. ${ }^{7}$

A number of authoritative geriatric medicine sources report that anticholinergic use may increase falls risk. Indeed, it is plausible that anticholinergic use could be related to falls as a result of their effect on the central nervous system (which may include ataxia, cognitive impairment, dizziness, and lightheadedness) as well as other possible effects, such as and mydriasis, causing a loss of accommodation and visual problems. However, it is important to note that many of these drugs have adverse effects independent of their anticholinergic effects (eg, sedation, orthostasis) that could increase falls. Despite this, findings from published research studies are mixed, with some studies showing an increased risk of falls with exposure to anticholinergics and others not. ${ }^{2,9-13}$ It is important to note that some of these prior studies showing an increased risk of falls with anticholinergic medication exposure are limited by focusing on single anticholinergic drug classes, assessing a single fall as the outcome, and lack of addressing the important potential source of bias, confounding by indication. We sought to conduct a longitudinal analysis to assess the association between anticholinergic use across multiple anticholinergic subclasses and recurrent falls, which addresses some limitations of prior studies.

\section{Methods}

\section{Study Design, Data Source, and Sample}

We used data from the Health, Aging and Body Composition (Health ABC) study, a population-based, prospective, longitudinal, observational study of community-dwelling older adults. This study was approved by the University of California San Francisco, University of Pittsburgh, and University of Tennessee Memphis institutional review boards, and informed consent was obtained from each participant prior to data collection. The baseline sample included 3075 black and white men and women 70 to 79 years old, who 
reported no difficulty walking one-fourth of a mile, climbing 10 steps, or performing basic activities of daily living and lived in specified zip codes surrounding Pittsburgh, PA, and Memphis, TN. ${ }^{14}$ The sample for the current analysis included 2948 older adults at baseline, with complete medication use and fall data in the ensuing year, who were followed through year 6 for anticholinergic medications and year 7 for recurrent falls. Participants were excluded from the current analysis if they did not report any medication use or if they did not have fall data available at the respective assessments.

\section{Data Collection and Management}

Participants were seen annually during a clinic or home visit, and detailed physiological and self-report questionnaire measurements (including demographics, health behavior/status, medications, and access-to-care factors) were collected. ${ }^{14}$ Detailed medication data were collected in the clinic or at home about products taken in the previous month using a "brown bag" review method. ${ }^{15,16} \mathrm{~A}$ similar data collection approach was used for telephone interviews if the participants were unable to be seen in person. Studies have shown that medication use information collected by either the brown bag or telephone methods is highly accurate and concordant with information about dispensed prescription drugs in claims data. ${ }^{17,18}$ For all medications, the interviewer recorded the name, strength, prescription type (prescription or over-the-counter), dosage form, and the number of dosage forms the respondents said they had used the previous day, week, or month. The medication data were edited and coded using the Iowa Drug Information System (IDIS) Drug Vocabulary and Thesaurus. ${ }^{15}$ IDIS is a hierarchical coding system with 8-character unique codes for specific drug ingredients, and chemical and therapeutic categories. This therapeutic category code allows drugs to be assigned to 1 of 20 major therapeutic classes and 200 subclasses based on an expanded version of the American Hospital Formulary Services format. ${ }^{19}$

\section{Primary Outcome}

Those with recurrent falls were defined as participants who reported landing on the floor or ground 2 or more times in the previous 12 months. This method of fall recall (in the previous 12 months) has been shown to be highly specific (91\%-95\%) in comparison with that reported using more frequent assessments. ${ }^{20}$

\section{Primary and Secondary Medication Exposures}

Select medications with anticholinergic properties were grouped based on 8 therapeutic drug classes used by the 2015 AGS Beers Criteria for Potentially Inappropriate Medication Use in Older Adults. ${ }^{21}$ The appendix shows the specific agents for these 8 therapeutic drug classes that include (1) antiarrhythmics (ie, disopyramide); (2) antihistamines; (3) antidepressants; (4) antimuscarinics; (5) antiparkinson agents; (6) antipsychotics; (7) antispasmodics; (8) and skeletal muscle relaxants. ${ }^{21}$ Of note, some of the anticholinergic medications listed in the Beers Criteria were not included in the current analysis because they were either not used by participants or not on the market during the study period. This anticholinergic medication list is consistent with a list from a recently published study. ${ }^{22}$ The primary independent variable was any use of medications from any of the 8 categories. ${ }^{21}$ Any use of anticholinergic medication use exposure information came from the previous year's assessment (eg, year 1 anticholinergic use and year 2 falls) for each wave (5 waves). As a 
result, medication exposure always preceded the falls outcome to establish an appropriate temporal relationship. To evaluate the possibility of a dose-response relationship, using a previously published approach, the daily dose for regularly scheduled medications (ie, excluding as needed or "prn" use) was calculated for current users for each individual anticholinergic medication by multiplying the number of units of the dosage form taken the previous day by the strength of the medication reported at the interview. ${ }^{6}$ The daily dose was then converted to a standardized daily dose (SDD) by dividing it by the minimum effective geriatric dose per day as noted in a standard reference (see the appendix). ${ }^{23}$ Thus, a person taking 1.0 standardized anticholinergic drug unit would have taken the minimum recommended effective daily dose for one agent. The standardized dose was summed over all anticholinergics, regardless of class, taken daily. To examine the impact of duration, long-term use was operationally defined as $\geq 2$ and short-term use as $<2$ years. ${ }^{6}$ Finally, to examine the potential risk of classes of anticholinergic drugs, for analysis purposes, we operationally took into account the low prevalence of use for some of the drugs in these 8 therapeutic classes and further grouped these agents by their primary indications into 4 clinically relevant categories: (1) first-generation antihistamines used for allergies and to relieve emesis and vertigo, (2) antidepressants/antipsychotics, (3) genitourinary antimuscarinics/gastrointestinal antispasmodics, and (4) miscellaneous (skeletal muscle relaxants, antiparkinson agents, and antiarrhythmics).

\section{Covariates}

To address potential confounding, we controlled for several demographic, health status/ behavior, and access-to-care factors. ${ }^{6,7}$ Demographic factors included age, sex, race, site, education (less than a high school education, high school graduate, and post-secondary education), and marital status (never married, married, previously married).

Health behavior factors included smoking status and alcohol use. Health status factors included self-reported pulmonary, coronary heart, peripheral artery, congestive heart, and cerebrovascular disease; diabetes; hypertension; hearing impairment; vision (excellent/good sight, fair sight, and poor to completely blind); and body mass index (underweight/normal, $<24.9$; overweight, 25.0-29.9; and obese, $230 \mathrm{~kg} / \mathrm{m}^{2}$ ). Self-rated global health was dichotomized as excellent/very good/good versus fair/poor. We created a time-varying dichotomous variable for exposure to any other drug not included in the primary independent variable that increases the risk of falls (nonanticholinergic central nervous system medications, including benzodiazepines, antipsychotics, and opioids). ${ }^{6}$ A continuous time-varying variable was created for the total number of prescription medications (excluding drugs that increase falls and anticholinergic drugs) per participant. Access-tocare factors included dichotomous variables for hospitalization in the previous 12 months and having a private physician, prescription insurance, and flu shot in the previous 12 months. ${ }^{24}$

Anticholinergics can be used for a variety of conditions. Therefore, to control for potential confounding by indication, we created time-varying dichotomous variables for depressive symptoms (Short Center for Epidemiologic Studies-Depression Scale 210 ) for which tricyclic antidepressants may be used ${ }^{25}$; cognitive impairment (The Modified Mini-Mental 
State Test $[3 \mathrm{MS}]<80$ ), for which antipsychotics may be used to treat behavioral symptoms $^{26}$; back pain in past 12 months, for which skeletal muscle relaxants may be used; anxiety symptoms, for which several anticholinergic agents may be used ${ }^{27}$; sleep problems, for which antihistamines may be used; and urinary problems, for which urinary antispasmodics may be used.

\section{Statistical Analysis}

We used appropriate descriptive statistics for summarization and generalized estimating equations (GEEs) for eliciting the main findings. ${ }^{28,29}$ First, we assessed the unadjusted association between anticholinergic use and recurrent falls over time. Second, a priori covariates that may affect recurrent falls were included: site, cognitive impairment, depressive symptoms, non-anticholinergic drugs that increase the risk of falls, urinary problems, back pain, and sleep problems. Finally, additional covariates were selected using a forward stepwise selection approach applied separately for each of 3 domains (demographic, health status/behavior, and access-to-care domains). Stepwise detected covariates and those deemed important a priori were included in the final GEE model. The primary analysis examined any use of anticholinergics as the main independent variable of interest. For secondary analyses, each of the 4 anticholinergic subclasses based on indication was run as a separate model, controlling for use of anticholinergics in other subclasses. In addition, dose and duration of anticholinergic use were evaluated for any association with recurrent falls. All analyses were conducted using SAS software (version 9.3; SAS Institute, Cary, NC) with GENMOD procedure to obtain the main results.

\section{Results}

At baseline, the mean age was 73.6 years; $51.6 \%$ were female; and $40.8 \%$ were black (Table 1). In addition, approximately $40 \%$ reported back pain in the past 12 months, and the vast majority had good-to-excellent self-reported health. Baseline characteristics of anticholinergic users and nonusers are shown in Table 1. Anticholinergic users were more likely to report fair/poor self-rated health, urinary problems, pulmonary disease, back pain in the past 12 months, sleep problems, anxiety symptoms, hospitalization in the previous 12 months, and use of more medications at baseline. Important differences between groups were controlled for in multivariable analyses.

Table 2 shows the prevalence of anticholinergic use over time. At baseline, $16 \%$ reported taking one or more anticholinergics, with antihistamines being the most common class used $(9.8 \%)$. Among users, half took an anticholinergic for at least 2 years, and one-quarter were taking them in doses $>2$ SDDs. By year 6 , the prevalence of anticholinergic use remained consistent at $15.8 \%$, with antihistamines remaining the most common category used $(6.6 \%)$. At year $2,8 \%$ of participants reported having $\geq 2$ falls in the previous year. This rate remained somewhat stable over the next 4 waves ( $7.5 \%$ to $10.4 \%)$.

Table 3 shows the results of the bivariate and multivariable GEE analyses, controlling for demographics, health status/behavior, and access-to-care factors. Bivariate analysis showed statistically significant associations for every model except low-dose anticholinergic use. However, these associations were attenuated after adjusting for keyvariables. Specifically, 
controlling for demographics, health status/behaviors, and access-to-care factors, a 34\% increase in the likelihood of recurrent falls in anticholinergic users (adjusted odds ratio [OR] $=1.34 ; 95 \% \mathrm{CI}=0.93-1.93$ ) was observed, but the results were not statistically significant; similar results were found with higher doses and longer duration of use. In addition, none of the anticholinergic subclasses was found to be associated with recurrent falls.

\section{Discussion}

This study presents some of the first data to longitudinally assess the association between any anticholinergic use-including both prescription and over-the-counter drug use- and recurrent falls in community-dwelling older adults. We found a $34 \%$ increase in likelihood of recurrent falls in anticholinergic users, but the results were not statistically significant after accounting for indication of use and other fall-related risk factors. Given our sample size and the prevalence of any anticholinergic use and recurrent falls, we had sufficient power to detect an OR this small ( $\beta$ set to $80 \%$ and a set to 0.05 ). Our secondary analyses also did not find a dose- or duration-response relationship or an increased risk of recurrent falls with any of the 4 exposure categories, based on indication for use. It is also notable that the use of antimuscarinics/antispasmodics, indicated for urinary incontinence and gastrointestinal problems such as irritable bowel syndrome, which do not have sedative properties or cause orthostasis, did not increase the risk of recurrent falls.

These findings are consistent with a study from more than 7700 community-dwelling older Canadians using 10 years of prospective data from the Canadian Multicentre Osteoporosis Study. ${ }^{9}$ That study by Fraser et $\mathrm{al}^{9}$ found that anticholinergic use was associated with single falls $(\mathrm{OR}=1.50 ; 95 \% \mathrm{CI}=1.14-1.98)$ in unadjusted analyses, but the association was attenuated after accounting for indication and other potential confounders (adjusted OR = $1.25 ; 95 \% \mathrm{CI}=0.91-1.72$ ). Despite differences in study design, our findings are strikingly similar.

In contrast, other previous studies have found anticholinergic use to be significantly associated with falls in older adults, but this work may have important limitations. Aizenberg et al ${ }^{10}$ conducted a case-control study over 4 years among elderly psychiatric inpatients and reported that anticholinergic burden score—an additive score based on the anticholinergic effect of each psychotropic compound that a patient received—was significantly associated with inpatient falls. This study did not control for common indications for use of these agents or for other important fall risk factors. In addition, the measure of anticholinergic exposure included only psychotropic medications, a small subset of the potential anticholinergic burden, and used an inpatient population, which arguably faces substantially different fall risk from communitydwelling older adults. Berdot et al ${ }^{12}$ found a significant increased risk of falls in regular anticholinergic users in a sample of 6343 community-dwelling elders from France. However, current anticholinergic use was not significantly associated with falls in this study. Moreover, a recently published study by Alvarez et al ${ }^{13}$ primarily restricted to elderly males in the Veterans Administration (VA) found that the use of first-generation antihistamines increased the risk of emergency room visits or hospitalization caused by falls/fractures. Besides the threat to generalizability given the sample gender, the study findings could also have been influenced by potential 
misclassification bias because of inability to capture fall outcomes reporting to non-VA facilities and/or over the-counter anticholinergic use.

One possible reason for the inconsistency across research studies may be a result of inadequate control for underlying medical conditions for which anticholinergic medications are used (eg, back pain, depression). The potential for confounding by indication poses a major threat to the validity of studies assessing medication use in older adults. In the work reported here, we controlled for key conditions for which older adults might use anticholinergics. Taken together, our findings in addition to the results of Fraser et al, ${ }^{9}$ suggest that the observed relationship between anticholinergic drugs and falls in communitydwelling elders appears to be largely a function of the underlying conditions for which they are prescribed. Simply put, although anticholinergic drugs should generally be avoided in the elderly, individual risks and benefits for each patient should be carefully considered. ${ }^{2}$

There are important potential limitations to our study. First, the main outcome of recurrent falls was retrospectively collected via self-report. However, it is a highly specific method compared with self-reporting of falls via diary. ${ }^{20}$ Use of additional methods may have led to extra case finding, potentially leading to statistically significant point estimates. Second, medication data were collected at fixed annual assessments, preventing documentation of the exact date when anticholinergics were initiated, changed, or discontinued. Third, it is always possible that there is residual confounding. Fourth, the question of statistical power may be a concern. It is possible that we may have had insufficient power to detect a statistically significant OR for our secondary exposure variables, which involved smaller numbers of participants than those in our primary exposure variable of any anticholinergic medication use. Finally, our analysis focused on older (albeit a rather narrow age range), well-functioning, community-dwelling black and white men and women from the Memphis and Pittsburgh areas, and the generalizability to older adults in general or other regions, of poorer health status, or in different care settings is unknown.

\section{Conclusion}

In conclusion, increased point estimates suggest an association of anticholinergic use with recurrent falls, but the associations did not reach statistical significance. Future studies are needed to obtain more definitive evidence and examine other measures of anticholinergic burden and their associations with more intermediate adverse effects such as cognitive function.

\section{Acknowledgments}

We would like to thank Yihuang Kang, $\mathrm{PhD}$, and Robert M. Boudreau, $\mathrm{PhD}$, for their advice regarding Health $\mathrm{ABC}$ data and data analysis.

Funding The author(s) disclosed receipt of the following financial support for the research, authorship, and/or publication of this article: This research was primarily supported by National Institute on Aging (NIA) grants and contracts (P30AG024827, T32 AG021885, K07AG033174, R01AG028050). This research was also supported in part by the Intramural Research program of the National Institutes of Health, NIA (N01-AG-6-2101, N01AG-6-2103, and N01-AG-6-2106), and a National Institute of Nursing research grant (R01NR012459). 


\section{Appendix}

Highly Anticholinergic Drugs and Minimum Effective Geriatric Daily Doses. ${ }^{a}$

\begin{tabular}{|c|c|c|}
\hline Category & Drug Name & $\begin{array}{r}\text { Minimum Effective } \\
\text { Daily Dose } a\end{array}$ \\
\hline Antiarrhythmics & Disopyramide & 400 \\
\hline \multirow[t]{14}{*}{ Antihistamines } & Brompheniramine & 12 \\
\hline & Carbinoxamine & 12 \\
\hline & Chlorpheniramine & 4 \\
\hline & Clemastine & 2 \\
\hline & Cyproheptadine & 4 \\
\hline & Dexchlorpheniramine & 8 \\
\hline & Dimenhydrinate & 200 \\
\hline & Diphenhydramine & 50 \\
\hline & Doxylamine & 5 \\
\hline & Hydroxyzine & 75 \\
\hline & Meclizine & 25 \\
\hline & Phenyltoloxamine & 30 \\
\hline & Promethazine & 50 \\
\hline & Triprolidine & 10 \\
\hline \multirow[t]{9}{*}{ Antidepressants } & Amitriptyline & 10 \\
\hline & Clomipramine & 25 \\
\hline & Desipramine & 10 \\
\hline & Doxepin & 10 \\
\hline & Imipramine & 10 \\
\hline & Nortriptyline & 10 \\
\hline & Paroxetine & 10 \\
\hline & Protriptyline & - \\
\hline & Trimipramine & 50 \\
\hline \multirow[t]{7}{*}{ Antimuscarinics } & Darifenacin & - \\
\hline & Fesoterodine & - \\
\hline & Flavoxate & 300 \\
\hline & Oxybutynin & 5 \\
\hline & Solifenacin & - \\
\hline & Tolterodine & 2 \\
\hline & Trospium & - \\
\hline \multirow[t]{2}{*}{ Antiparkinson agents } & Benztropine & 0.5 \\
\hline & Trihexyphenidyl & 6 \\
\hline \multirow[t]{6}{*}{ Antipsychotics } & Chlorpromazine & 10 \\
\hline & Clozapine & - \\
\hline & Loxapine & 20 \\
\hline & Olanzapine & 2.5 \\
\hline & Perphenazine & - \\
\hline & Prochlorperazine & 15 \\
\hline
\end{tabular}

Ann Pharmacother. Author manuscript; available in PMC 2015 November 01. 


\begin{tabular}{llr}
\hline Category & Drug Name & $\begin{array}{r}\text { Minimum Effective } \\
\text { Daily Dose }^{\boldsymbol{a}}\end{array}$ \\
\hline & Trifluoperazine & - \\
& Thioridazine & 10 \\
Antispasmodics & Atropine (oral) & 0.05 \\
& Belladonna alkaloids & Comprising atropine, hyoscyamine, and scopolamine \\
& Clidinium & 7.5 \\
& Dicyclomine & 40 \\
& Hyoscyamine products & 0.31 \\
& Propantheline & 22.4 \\
& Scopolamine (oral) & 0.0195 \\
Ckeletal muscle relaxants & Cyclobenzaprine & 5 \\
& Orphenadrine & 200 \\
\hline$a$ Minimum effective doses not provided for medications that participants did not report using or that were not on the \\
market during the study period.
\end{tabular}

\section{References}

1. Rémillard AJ. A pharmacoepidemiological evaluation of anticholinergic prescribing patterns in the elderly. Pharmacoepidemiol Drug Saf. 1996; 5:155-164. [PubMed: 15073832]

2. Ness J, Hoth A, Barnett M, Shorr RI, Kaboli PJ. Anticholinergic medications in communitydwelling older veterans: prevalence of anticholinergic symptoms, symptom burden, and adverse drug events. Am J Geriatr Pharmacother. 2006; 4:42-51. [PubMed: 16730620]

3. Sumukadas D, McMurdo ME, Mangoni AA, Guthrie B. Temporal trends in anticholinergic medication prescription in older people: repeated cross-sectional analysis of population prescribing data. Age Ageing. 2014; 43:515-521. [PubMed: 24334709]

4. Huang AR, Mallet L, Rochefort CM, Eguale T, Buckeridge DL, Tamblyn R. Medication-related falls in the elderly: causative factors and preventive strategies. Drugs Aging. 2012; 29:359-376. [PubMed: 22550966]

5. Hanlon JT, Landerman LR, Fillenbaum GG, Studenski S. Falls in African American and white community-dwelling elderly residents. J Gerontol A Biol Sci Med Sci. 2002; 57:473-478.

6. Hanlon JT, Boudreau RM, Roumani YF, et al. Number and dosage of central nervous system medications on recurrent falls in community elders: the Health, Aging and Body Composition study. J Gerontol Med Sci. 2009; 64A:492-498.

7. King, MB. Falls. In: Halter, J.; Ouslander, J.; Tinetti, M.; Studenski, S.; High, K.; Asthana, S., editors. Hazzard's Geriatric Medicine and Gerontology. 6th ed.. New York, NY: McGraw-Hill; 2009. p. 659-670.

8. Tinetti ME. Clinical practice: preventing falls in elderly persons. N Engl J Med. 2003; 348:42-49. [PubMed: 12510042]

9. Fraser LA, Adachi JD, Leslie WD, et al. Effect of anticholinergic medications on falls, fracture risk, and bone mineral density over a 10-year period. Ann Pharmacother. 2014; 48:954-961. [PubMed: 24816210]

10. Aizenberg D, Sigler M, Weizman A, Barak Y. Anticholinergic burden and the risk of falls among elderly psychiatric inpatients: a 4-year case-control study. Int Psychogeriatr. 2022; 14:307-310. [PubMed: 12475091]

11. Wilson NM, Hilmer SN, March LM, et al. Associations between drug burden index and falls in older people in residential aged care. J Am Geriatr Soc. 2011; 59:875-880. [PubMed: 21539525]

12. Berdot S, Bertrand M, Dartigues JF, et al. Inappropriate medication use and risk of falls: a prospective study in a large community-dwelling elderly cohort. BMC Geriatr. 2009; 9:30. [PubMed: 19627577] 
13. Alvarez CA, Mortensen EM, Makris UE, et al. Association of skeletal muscle relaxers and antihistamines on mortality, hospitalizations, and emergency department visits in elderly patients: a nationwide retrospective cohort study. BMC Geriatr. 2015; 15:2. [PubMed: 25623366]

14. Newman AB, Haggerty CL, Kritchevsky SB, Nevitt MC, Simonsick EM. Walking performance and cardiovascular response: associations with age and morbidity: the Health, Aging and Body Composition Study. J Gerontol. 2003; 58:M715-M720.

15. Pahor M, Chrischilles EA, Guralnik JM, Brown SL, Wallace RB, Carbonin P. Drug data coding and analysis in epidemiologic studies. Eur J Epidemiol. 1994; 10:405-411. [PubMed: 7843344]

16. Marcum ZA, Perera S, Donohue JM, et al. Analgesic use for knee and hip osteoarthritis in community-dwelling elders. Pain Med. 2011; 12:1628-1636. [PubMed: 21992521]

17. Pit SW, Byles JE, Cockburn J. Accuracy of telephone self-report of drug use in older people and agreement with pharmaceutical claims data. Drug Aging. 2008; 25:71-80.

18. Caskie GI, Willis SL, Schaie KW, Zanjani FA. Congruence of medication information from a brown bag data collection and pharmacy records: findings from the Seattle longitudinal study. Exp Aging Res. 2006; 32:79-103. [PubMed: 16293570]

19. McEvoy, GK., editor. AHFS Drug Information 2004. Bethesda, MD: American Society of Hospital Pharmacists; 2011.

20. Ganz DA, Higashi T, Rubenstein LZ. Monitoring falls in cohort studies of community dwelling older people: effect of the recall interval. J Am Geriatr Soc. 2005; 53:2190-2194. [PubMed: 16398908]

21. The American Geriatrics Society 2015 Beers Criteria Update Expert Panel. American Geriatrics Society 2015 updated Beers criteria for potentially inappropriate medication use in older adults. J Am Geriatr Soc. In press.

22. Gray SL, Anderson ML, Dublin S, et al. Cumulative use of strong anticholinergics and incident dementia: a prospective cohort study. JAMA Intern Med. 2015; 175:401-407. [PubMed: 25621434]

23. Semla, TP.; Beizer, JL.; Higbee, MD., editors. Geriatric Dosage Handbook. 19th ed.. Hudson, OH: Lexi-Comp; 2014.

24. Rooks RN, Simonsick EM, Klesges LM, Newman AB, Ayonayon HN, Harris TB. Racial disparities in health care access and cardiovascular indicators in black and white older adults in the Health ABC study. J Aging Health. 2008; 20:599-614. [PubMed: 18625758]

25. Radloff LS. The CES-D scale: a self-report depression scale for research use in the general population. Appl Psychol Meas. 1977; 1:385-401.

26. Teng EL, Chui HC. The Modified Mini-Mental State (3MS) examination. J Clin Psychiatry. 1987; 48:314-318. [PubMed: 3611032]

27. Mehta KM, Yaffe K, Brenes GA, et al. Anxiety symptoms and decline in physical function over 5 years in the Health, Aging and Body Composition Study. J Am Geriatr Soc. 2007; 55:265-270. [PubMed: 17302665]

28. Liang K, Zeger S. Longitudinal data analysis using generalized linear models. Biometrika. 1986; 73:13-22.

29. Diggle, PJ.; Heagerty, P.; Liang, K.; Zeger, S., editors. Analysis of Longitudinal Data. 2nd ed.. New York, NY: Oxford University Press; 2002. 


\section{Table 1}

Characteristics of the Sample at Baseline $(n=2948)$.

\begin{tabular}{|c|c|c|c|}
\hline Variables & $\begin{array}{c}\text { Anticholinergic Use, Mean } \pm \\
\text { SD } \\
\text { or } n(\%), n=467\end{array}$ & $\begin{array}{l}\text { No Anticholinergic Use, } \\
\text { Mean } \\
\pm \text { SD or } n(\%), \mathbf{n}=\mathbf{2 4 8 1}\end{array}$ & $P$ Value \\
\hline \multicolumn{4}{|l|}{ Sociodemographics } \\
\hline Female gender & $308(65.9)$ & $1214(48.9)$ & $<0.0001$ \\
\hline Black race & $160(34.3)$ & $1043(42.0)$ & 0.002 \\
\hline Age, mean (SD) & $73.6(2.8)$ & $73.6(2.9)$ & 0.71 \\
\hline Pittsburgh site & $189(40.5)$ & $1277(51.5)$ & $<0.0001$ \\
\hline Education & & & 0.274 \\
\hline Postsecondary & $211(45.2)$ & $1049(42.3)$ & \\
\hline High school graduate & $153(32.8)$ & $801(32.3)$ & \\
\hline$<$ High school & $102(21.8)$ & $625(25.2)$ & \\
\hline Married & $208(44.5)$ & $1323(53.3)$ & $<0.001$ \\
\hline \multicolumn{4}{|l|}{ Health behaviors/status } \\
\hline Current smoker & $52(11.1)$ & $250(10.1)$ & 0.493 \\
\hline Alcohol use ( $\geq 1$ drink per week) & $126(27.0)$ & $721(29.1)$ & 0.363 \\
\hline Pulmonary disease & $60(12.9)$ & $238(9.6)$ & 0.032 \\
\hline Coronary heart disease & $94(20.1)$ & $537(21.6)$ & 0.459 \\
\hline Congestive heart disease & $11(2.4)$ & $74(3.0)$ & 0.463 \\
\hline Cerebrovascular disease & $43(9.2)$ & $188(7.6)$ & 0.229 \\
\hline Diabetes & $70(15.0)$ & $370(14.9)$ & 0.974 \\
\hline Hypertension & $232(49.7)$ & $1266(51.0)$ & 0.593 \\
\hline Peripheral arterial disease & $21(4.5)$ & $128(5.2)$ & 0.522 \\
\hline Hearing impairment & $42(9.0)$ & $220(8.9)$ & 0.923 \\
\hline Vision problems & & & 0.193 \\
\hline Excellent/good sight & $375(80.3)$ & $1971(79.4)$ & \\
\hline Fair sight & $85(18.2)$ & $434(17.5)$ & \\
\hline Poor to completely blind & $7(1.5)$ & $74(3.0)$ & \\
\hline Body mass index $\left(\mathrm{kg} / \mathrm{m}^{2}\right)$ & & & 0.256 \\
\hline Underweight/normal $(<24.9)$ & $158(33.8)$ & $789(31.8)$ & \\
\hline Overweight (25.0-29.9) & $183(39.2)$ & $1074(43.3)$ & \\
\hline Obese (30+) & $126(27.0)$ & $618(24.9)$ & \\
\hline Self-rated health & & & 0.035 \\
\hline Excellent/Very good/Good & $378(80.9)$ & $2101(84.7)$ & \\
\hline Fair/Poor & $89(19.1)$ & $376(15.2)$ & \\
\hline $\begin{array}{l}\text { Drugs that increase risk of falls (benzodiazepines, } \\
\text { antipsychotics, opioids) }\end{array}$ & $167(35.8)$ & $218(8.8)$ & $<0.0001$ \\
\hline Number of prescription medications $a, b$ & $2.1(2.4)$ & $1.7(1.9)$ & 0.0001 \\
\hline \multicolumn{4}{|c|}{ Health status (conditions for which anticholinergics are prescribed) } \\
\hline Depressive symptoms (Short CES-D $\geq 10)^{a}$ & $40(8.6)$ & $128(5.2)$ & 0.003 \\
\hline Cognitive impairment $(3 \mathrm{MS}<80)^{a}$ & $29(6.2)$ & $255(10.3)$ & 0.006 \\
\hline
\end{tabular}




\begin{tabular}{|c|c|c|c|}
\hline Variables & $\begin{array}{c}\text { Anticholinergic Use, Mean } \pm \\
\text { SD } \\
\text { or } n(\%), n=467\end{array}$ & $\begin{array}{l}\text { No Anticholinergic Use, } \\
\text { Mean } \\
\pm \text { SD or } n(\%), n=2481\end{array}$ & $P$ Value \\
\hline Back pain in past 12 months ${ }^{a}$ & $224(48.0)$ & $1017(41.0)$ & 0.005 \\
\hline Anxiety symptoms ${ }^{a}$ & $100(21.4)$ & $314(12.7)$ & $<0.0001$ \\
\hline Sleep problems ${ }^{a}$ & $135(28.9)$ & $556(22.4)$ & 0.002 \\
\hline Urinary problems ${ }^{a}$ & $213(45.6)$ & $928(37.4)$ & 0.001 \\
\hline \multicolumn{4}{|l|}{ Access to health care } \\
\hline Hospitalization in previous 12 months & $89(19.1)$ & $346(14.0)$ & 0.004 \\
\hline Private physician & $382(81.8)$ & $1937(78.1)$ & 0.071 \\
\hline Prescription insurance & $294(63.0)$ & $1567(63.2)$ & 0.939 \\
\hline Flu shot in previous 12 months & $339(72.6)$ & $1700(68.5)$ & 0.081 \\
\hline
\end{tabular}

Abbreviations: 3MS, Modified Mini-Mental Status Exam; CES-D, Center for Epidemiologic Studies Depression Scale; CNS, central nervous system.

${ }^{a}$ Time-varying.

${ }^{b}$ Excluding drugs that increase risk of falls and anticholinergic drugs. 
Table 3

Association Between Anticholinergic Use and Recurrent Falls, Controlling for Covariates.

\begin{tabular}{|c|c|c|}
\hline Anticholinergic Medication Use ${ }^{a}$ & Bivariate OR (95\% CI) & Adjusted OR $(95 \% \mathrm{CI})^{b}$ \\
\hline Any use & $1.92(1.62-2.27)$ & $1.34(0.93-1.93)$ \\
\hline Long duration ( $\geq 2$ years) & $2.15(1.72-2.70)$ & $1.36(0.84-2.21)$ \\
\hline Short duration & $1.76(1.43-2.17)$ & $1.32(0.83-2.10)$ \\
\hline SDD: $\geq 2$ & $2.62(1.99-3.46)$ & $1.54(0.84-2.82)$ \\
\hline SDD: $1-2$ & $2.13(1.69-2.68)$ & $1.40(0.80-2.45)$ \\
\hline SDD: $<1$ & $1.23(0.90-1.68)$ & $1.17(0.68-2.00)$ \\
\hline Specific class use ${ }^{c}$ & - & - \\
\hline Antihistamines & $1.64(1.30-2.07)$ & $1.40(0.91-2.13)$ \\
\hline Antidepressants/Antipsychotics & $2.07(1.56-2.76)$ & $1.14(0.59-2.18)$ \\
\hline Antimuscarinics/Antispasmodics & $1.93(1.48-2.53)$ & $1.26(0.64-2.48)$ \\
\hline
\end{tabular}

Abbreviations: OR, odds ratio; SDD, standardized daily dose.

${ }^{a}$ Reference group is No Use.

$b$

${ }^{b}$ Too few participants reported the use of miscellaneous agents to conduct our multivariable analyses that controlled for variables forced into the model (ie, site, cognitive impairment, depression, drugs that increase the risk of falls, urinary problems, back pain, and sleep problems) and those from forward selection procedures (ie, smoking, alcohol use, cerebrovascular disease, diabetes, vision problems, anxiety, and total number of prescription medications).

${ }^{c}$ Each anticholinergic subclass was run as a separate model and controlled for anticholinergic subclass use other than the subclass being evaluated. 